\title{
Edward Jenner and the history of smallpox and vaccination
}

\author{
STEFAN RIEDEL, MD, PHD
}

In science credit goes to the man who convinces the world, not the man to whom the idea first occurs. -FRANCIS GALTON

$\mathrm{F}$ Tor many centuries, smallpox devastated mankind. In modern times we do not have to worry about it thanks to the remarkable work of Edward Jenner and later developments from his endeavors. With the rapid pace of vaccine development in recent decades, the historic origins of immunization are often forgotten. Unfortunately, since the attack on the World Trade Center on September 11, 2001, the threat of biological warfare and bioterrorism has reemerged. Smallpox has been identified as a possible agent of bioterrorism (1). It seems prudent to review the history of a disease known to few people in the 21 st century.

Edward Jenner (Figure 1) is well known around the world for his innovative contribution to immunization and the ultimate eradication of smallpox (2). Jenner's work is widely regarded as the foundation of immunology-despite the fact that he was neither the first to suggest that infection with cowpox conferred specific immunity to smallpox nor the first to attempt cowpox inoculation for this purpose.

\section{SMALLPOX: THE ORIGIN OF A DISEASE}

The origin of smallpox as a natural dis-

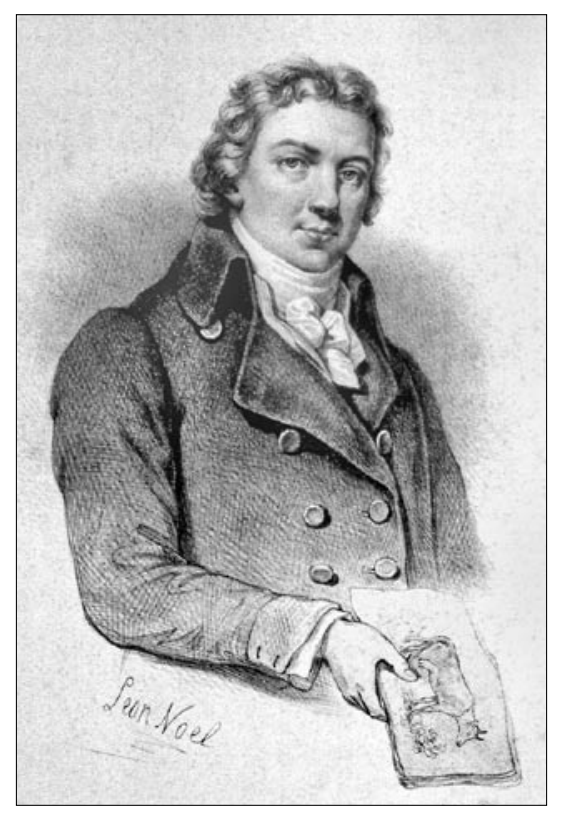

Figure 1. Edward Jenner (1749-1823). Photo courtesy of the National Library of Medicine. the Middle Ages. The disease greatly affected the development of Western civilization. The first stages of the decline of the Roman Empire (AD 108) coincided with a large-scale epidemic: the plague of Antonine, which accounted for the deaths of almost 7 million people (6). The Arab expansion, the Crusades, and the discovery of the West Indies all contributed to the spread of the disease.

Unknown in the New World, smallpox was introduced by the Spanish and Portuguese conquistadors. The disease decimated the local population and was instrumental in the fall of the empires of the Aztecs and the Incas. Similarly, on the eastern coast of North America, the disease was introduced by the early settlers and led to a decline in the native population. The devastating effects of smallpox also gave rise to one of the first examples of biological warfare $(1$, 7). During the French-Indian War (17541767), Sir Jeffrey Amherst, the commander of the British forces in North America, suggested the deliberate use of smallpox to diminish the American Indian population hostile to the British. Another factor contributing to smallpox in the Americas was the slave trade because many slaves came from regions in Africa where smallpox was endemic.

Smallpox affected all levels of society. In the 18th century in Europe, 400,000 people died annually of smallpox, and one third of the survivors went blind (4). The symptoms of smallpox, or the "speckled monster" as it was known in 18th-century England, appeared suddenly and the sequelae were devastating. The case-fatality rate varied from $20 \%$ to $60 \%$ and left most survivors with disfiguring scars. The case-fatality rate in infants was even higher, approaching $80 \%$ in London and $98 \%$ in Berlin during the late 1800s.

The word variola was commonly used for smallpox and had been introduced by Bishop Marius of Avenches (near Lausanne,

From the Department of Pathology, Baylor University Medical Center, Dallas, Texas.

Corresponding author: Stefan Riedel, MD, PhD, Department of Pathology, Baylor University Medical Center, 3500 Gaston Avenue, Dallas, Texas 75246 (e-mail: docriedel@aol.com). 
Switzerland) in AD 570. It is derived from the Latin word varius, meaning "stained," or from varus, meaning "mark on the skin." The term small pockes (pocke meaning sac) was first used in England at the end of the 15 th century to distinguish the disease from syphilis, which was then known as the great pockes (8).

\section{VARIOLATION AND EARLY ATTEMPTS OF TREATMENT}

It was common knowledge that survivors of smallpox became immune to the disease. As early as $430 \mathrm{BC}$, survivors of smallpox were called upon to nurse the afflicted (9). Man had long been trying to find a cure for the "speckled monster." During medieval times, many herbal remedies, as well as cold treatment and special cloths, were used to either prevent or treat smallpox. Dr. Sydenham (1624-1689) treated his patients by allowing no fire in the room, leaving the windows permanently open, drawing the bedclothes no higher than the patient's waist, and administering "twelve bottles of small beer every twenty-four hours" (10).

However, the most successful way of combating smallpox before the discovery of vaccination was inoculation. The word is derived from the Latin inoculare, meaning "to graft." Inoculation referred to the subcutaneous instillation of smallpox virus into nonimmune individuals. The inoculator usually used a lancet wet with fresh matter taken from a ripe pustule of some person who suffered from smallpox. The material was then subcutaneously introduced on the arms or legs of the nonimmune person. The terms inoculation and variolation were often used interchangeably. The practice of inoculation seems to have arisen independently when people in several countries were faced with the threat of an epidemic. However, inoculation was not without its attendant risks. There were concerns that recipients might develop disseminated smallpox and spread it to others. Transmission of other diseases, such as syphilis, via the bloodborne route was also of concern.

Inoculation, hereafter referred to as variolation, was likely practiced in Africa, India, and China long before the 18th century, when it was introduced to Europe (9). In 1670, Circassian traders introduced variolation to the Turkish "Ottoman" Empire. Women from the Caucasus, who were in great demand in the Turkish sultan's harem in Istanbul because of their legendary beauty, were inoculated as children in parts of their bodies where scars would not be seen. These women must also have brought the practice of variolation to the court of the Sublime Porte $(4,10)$.

Variolation came to Europe at the beginning of the 18th century with the arrival of travelers from Istanbul. In 1714, the Royal Society of London received a letter from Emanuel Timoni describing the technique of variolation, which he had witnessed in Istanbul. A similar letter was sent by Giacomo Pilarino in 1716. These reports described the practice of subcutaneous inoculation; however, they did not change the ways of the conservative English physicians.

It was the continued advocacy of the English aristocrat Lady Mary Wortley Montague (Figure 2) that was responsible for the introduction of variolation in England (10). In 1715, Lady Montague suffered from an episode of smallpox, which severely disfigured her beautiful face. Her 20-year-old brother died of the illness 18 months later. In 1717, Lady Montague's husband, Edward Wortley Montague, was appointed ambassador to the

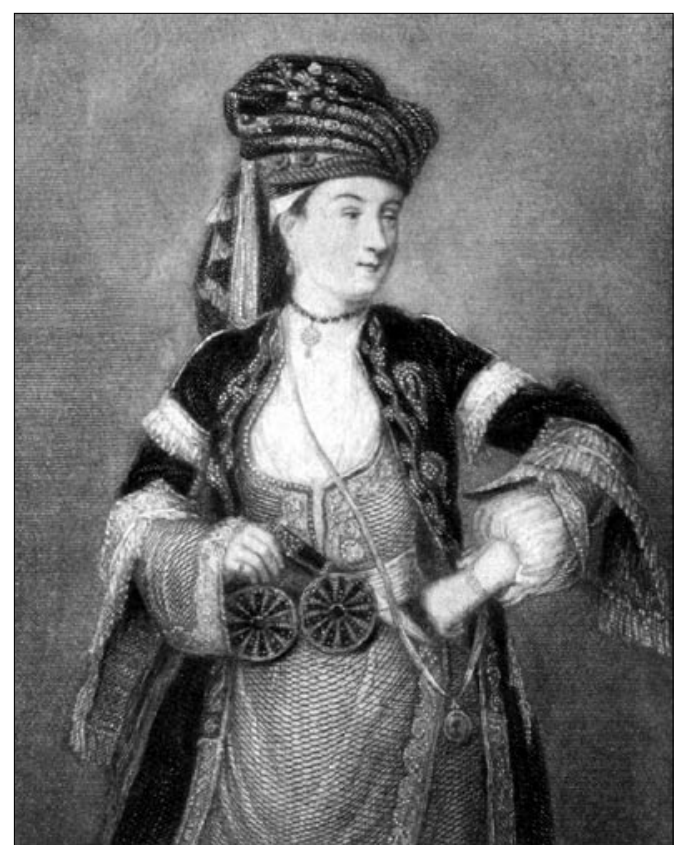

Figure 2. Lady Mary Wortley Montague (1689-1762). Photo courtesy of the National Library of Medicine.

Sublime Porte. A few weeks after their arrival in Istanbul, Lady Montague wrote to her friend about the method of variolation used at the Ottoman court. Lady Montague was so determined to prevent the ravages of smallpox that she ordered the embassy surgeon, Charles Maitland, to inoculate her 5 -year-old son. The inoculation procedure was performed in March 1718. Upon their return to London in April 1721, Lady Montague had Charles Maitland inoculate her 4-year-old daughter in the presence of physicians of the royal court.

After these first professional variolation procedures, word of the practice spread to several members of the royal family (11). Charles Maitland was then granted the royal license to perform a trial of variolation on six prisoners in Newgate on August 9, 1721. The prisoners were granted the king's favor if they submitted to this experiment. Several court physicians, members of the Royal Society, and members of the College of Physicians observed the trial. All prisoners survived the experiment, and those exposed to smallpox later proved to be immune. In the months following this very first trial, Maitland repeated the experiment on orphaned children, again with success. Finally, on April 17, 1722, Maitland successfully treated the two daughters of the Princess of Wales. Not surprisingly, the procedure gained general acceptance after this last success.

\section{THE SPREAD OF VARIOLATION}

In Europe, where the medical profession was relatively organized, the new methods of variolation became known quickly among physicians. Since there was also a demand for protection against smallpox, physicians soon began the variolation procedure on a massive scale. Although $2 \%$ to $3 \%$ of variolated persons died from the disease, became the source of another epidemic, or suffered from diseases (e.g., tuberculosis and syphilis) transmitted by the procedure itself, variolation rapidly gained popularity among both aristocratic and common people in Europe. The casefatality rate associated with variolation was 10 times lower than 
that associated with naturally occurring smallpox. In the 1750s more European princes died of smallpox, giving further impetus for the use of variolation (3). Among those variolated were Empress Marie-Therese of Austria and her children and grandchildren, Frederick II of Prussia, King Louis XVI of France and his children, and Catherine II of Russia and her son. King Frederick II of Prussia also inoculated all his soldiers. In fact, variolation was widely practiced in Europe until Jenner's discovery.

The regular practice of variolation reached the New World in 1721 (9). Under the guidance of the Rev. Cotton Mather (1663-1728) and Dr. Zabdiel Boylston (1679-1766), variolation became quite popular in the colonies. Mather, a graduate of Harvard College, was always very interested in science and medicine. When a ship from the West Indies carried persons sick with smallpox into Boston in 1721, an epidemic broke out in Boston and other parts of Massachusetts. Mather wrote a cautious letter recommending immediate variolation. However, he persuaded only Dr. Boylston. With Mather's support, Boylston immediately started a variolation program and continued to inoculate many volunteers, despite many adversaries in both the public and the medical community in Boston. As the disease spread, so did the controversy around Mather and Boylston (12). At the height of the epidemic, a bomb was thrown into Mather's house.

To make their point, Mather and Boylston used a statistical approach to compare the mortality rate of natural smallpox infection with that contracted by variolation. During the great epidemic of 1721, approximately half of Boston's 12,000 citizens contracted smallpox. The fatality rate for the naturally contracted disease was $14 \%$, whereas Boylston and Mather reported a mortality rate of only $2 \%$ among variolated individuals (12). This may have been the first time that comparative analysis was used to evaluate a medical procedure.

During the decades following the 1721 epidemic in Boston, variolation became more widespread in the colonies of New England. In 1766, American soldiers under George Washington were unable to take Quebec from the British troops, apparently because of a smallpox epidemic that significantly reduced the number of healthy troops (13). The British soldiers were all variolated. By 1777, Washington had learned his lesson: all his soldiers were variolated before beginning new military operations $(14,15)$. The success of variolation in the New World was not without effect on Europe. In fact, the rapid adoption of variolation in Europe can be directly traced to the efforts of Cotton Mather during the Boston smallpox epidemic in 1721. Although many British physicians remained skeptical even after Mather's success, the data he had published were eventually influential. Variolation was subsequently adopted in England and spread from there throughout Western Europe.

In 1757, an 8-year-old boy was inoculated with smallpox in Gloucester (4); he was one of thousands of children inoculated that year in England. The procedure was effective, as the boy developed a mild case of smallpox and was subsequently immune to the disease. His name was Edward Jenner.

\section{EDWARD JENNER}

Edward Jenner was born on May 17, 1749, in Berkeley, Gloucestershire, the son of the Rev. Stephen Jenner, vicar of Berkeley. Edward was orphaned at age 5 and went to live with his older brother. During his early school years, Edward developed a strong interest in science and nature that continued throughout his life. At age 13 he was apprenticed to a country surgeon and apothecary in Sodbury, near Bristol (16). The record shows that it was there that Jenner heard a dairymaid say, "I shall never have smallpox for I have had cowpox. I shall never have an ugly pockmarked face." It fact, it was a common belief that dairymaids were in some way protected from smallpox.

In 1764, Jenner began his apprenticeship with George Harwicke. During these years, he acquired a sound knowledge of surgical and medical practice (10). Upon completion of this apprenticeship at the age of 21, Jenner went to London and became a student of John Hunter, who was on the staff of St. George's Hospital in London. Hunter was not only one of the most famous surgeons in England, but he was also a well-respected biologist, anatomist, and experimental scientist. The firm friendship that grew between Hunter and Jenner lasted until Hunter's death in 1793. Although Jenner already had a great interest in natural science, the experience during the 2 years with Hunter only increased his activities and curiosity. Jenner was so interested in natural science that he helped classify many species that Captain Cook brought back from his first voyage. In 1772, however, Jenner declined Cook's invitation to take part in the second voyage (4).

Jenner occupied himself with many matters. He studied geology and carried out experiments on human blood (17). In 1784, after public demonstrations of hot air and hydrogen balloons by Joseph M. Montgolfier in France during the preceding year, Jenner built and twice launched his own hydrogen balloon. It flew 12 miles. Following Hunter's suggestions, Jenner conducted a particular study of the cuckoo. The final version of Jenner's paper was published in 1788 and included the original observation that it is the cuckoo hatchling that evicts the eggs and chicks of the foster parents from the nest $(17,18)$. For this remarkable work, Jenner was elected a fellow of the Royal Society. However, many naturalists in England dismissed his work as pure nonsense. For more than a century, antivaccinationists used the supposed defects of the cuckoo study to cast doubt on Jenner's other work. Jenner was finally vindicated in 1921 when photography confirmed his observation (19). At any rate, it is apparent that Jenner had a lifelong interest in natural sciences. His last work, published posthumously, was on the migration of birds.

In addition to his training and experience in biology, Jenner made great progress in clinical surgery while studying with John Hunter in London. Jenner devised an improved method for preparing a medicine known as tartar emetic (potassium antimony tartrate). In 1773, at the end of 2 years with John Hunter, Jenner returned to Berkeley to practice medicine. There he enjoyed substantial success, for he was capable, skillful, and popular. In addition to the practice of medicine, he joined two local medical groups for the promotion of medical knowledge and continued to write occasional medical papers $(4,18)$. He also played the violin in a musical club and wrote light verse and poetry. As a natural scientist, he continued to make many observations on birds and the hibernation of hedgehogs and collected many specimens for John Hunter in London.

While Jenner's interest in the protective effects of cowpox began during his apprenticeship with George Harwicke, it was 


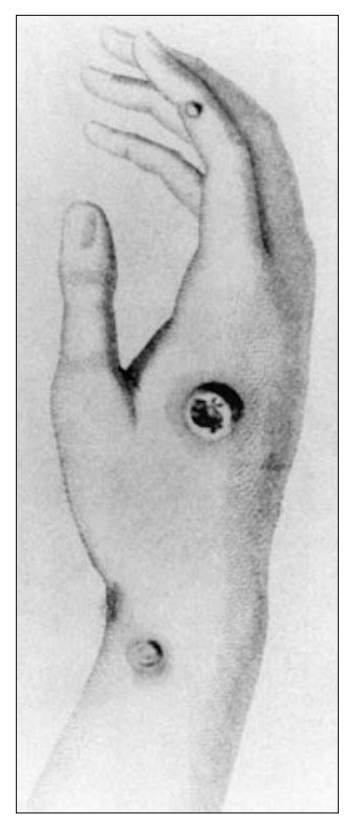

Figure 3. The hand of Sarah Nelms. Photo courtesy of the National Library of Medicine.
1796 before he made the first step in the long process whereby smallpox, the scourge of mankind, would be totally eradicated. For many years, he had heard the tales that dairymaids were protected from smallpox naturally after having suffered from cowpox. Pondering this, Jenner concluded that cowpox not only protected against smallpox but also could be transmitted from one person to another as a deliberate mechanism of protection. In May 1796, Edward Jenner found a young dairymaid, Sarah Nelms, who had fresh cowpox lesions on her hands and arms (Figure 3). On May 14, 1796, using matter from Nelms' lesions, he inoculated an 8 -year-old boy, James Phipps. Subsequently, the boy developed mild fever and discomfort in the axillae. Nine days after the procedure he felt cold and had lost his appetite, but on the next day he was much better. In July 1796, Jenner inoculated the boy again, this time with matter from a fresh smallpox lesion. No disease developed, and Jenner concluded that protection was complete (10).

In 1797, Jenner sent a short communication to the Royal Society describing his experiment and observations. However, the paper was rejected. Then in 1798, having added a few more cases to his initial experiment, Jenner privately published a small booklet entitled An Inquiry into the Causes and Effects of the Variolae Vaccinae, a disease discovered in some of the western counties of England, particularly Gloucestershire and Known by the Name of Cow Pox $(18,10)$. The Latin word for cow is vacca, and cowpox is vaccinia; Jenner decided to call this new procedure vaccination. The 1798 publication had three parts. In the first part Jenner presented his view regarding the origin of cowpox as a disease of horses transmitted to cows. The theory was discredited during Jenner's lifetime. He then presented the hypothesis that infection with cowpox protects against subsequent infection with smallpox. The second part contained the critical observations relevant to testing the hypothesis. The third part was a lengthy discussion, in part polemical, of the findings and a variety of issues related to smallpox. The publication of the Inquiry was met with a mixed reaction in the medical community.

Jenner went to London in search of volunteers for vaccination. However, after 3 months he had found none. In London, vaccination became popular through the activities of others, particularly the surgeon Henry Cline, to whom Jenner had given some of the inoculant (4). Later in 1799, Drs. George Pearson and William Woodville began to support vaccination among their patients. Jenner conducted a nationwide survey in search of proof of resistance to smallpox or to variolation among persons who had cowpox. The results of this survey confirmed his theory. Despite errors, many controversies, and chicanery, the use of vaccination spread rapidly in England, and by the year 1800, it had also reached most European countries (10).

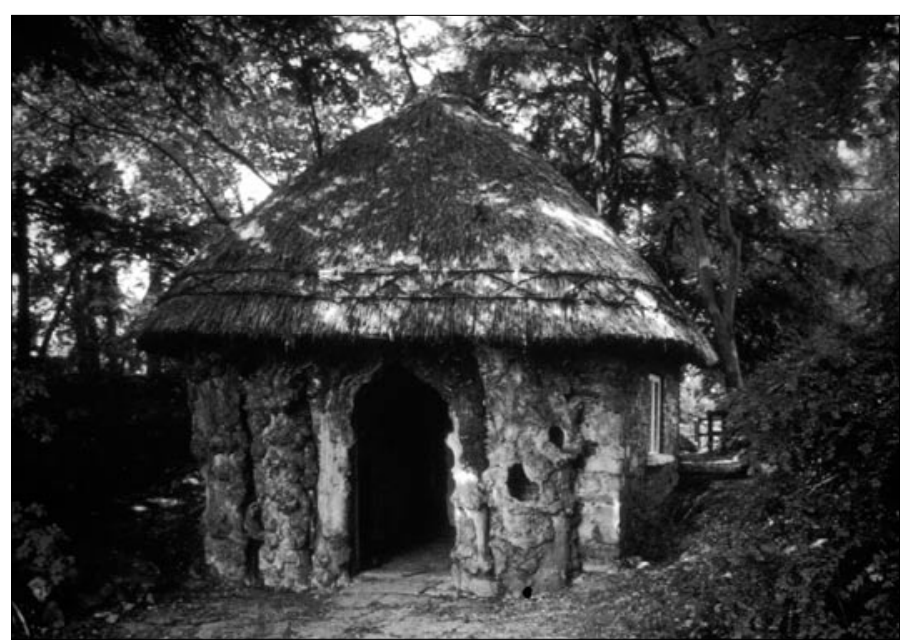

Figure 4. The Temple of Vaccinia. Photo courtesy of the Jenner Museum, Berkeley, Gloucestershire, England.

Although sometimes embarrassed by a lack of supply, Jenner sent vaccine to his medical acquaintances and to anyone else who requested it. After introducing cowpox inoculation in their own districts, many recipients passed the vaccine on to others. Dr. John Haygarth (of Bath, Somerset) received the vaccine from Edward Jenner in 1800 and sent some of the material to Benjamin Waterhouse, professor of physics at Harvard University. Waterhouse introduced vaccination in New England and then persuaded Thomas Jefferson to try it in Virginia. Waterhouse received great support from Jefferson, who appointed him vaccine agent in the National Vaccine Institute, an organization set up to implement a national vaccination program in the United States (20).

Although he received worldwide recognition and many honors, Jenner made no attempt to enrich himself through his discovery. He actually devoted so much time to the cause of vaccination that his private practice and his personal affairs suffered severely. The extraordinary value of vaccination was publicly acknowledged in England, when in 1802 the British Parliament granted Edward Jenner the sum of $£ 10,000$. Five years later the Parliament awarded him $£ 20,000$ more. However, he not only received honors but also found himself subjected to attacks and ridicule. Despite all this, he continued his activities on behalf of the vaccination program. Gradually, vaccination replaced variolation, which became prohibited in England in 1840.

Jenner married in 1788 and fathered four children. The family lived in the Chantry House, which became the Jenner Museum in 1985. Jenner built a one-room hut in the garden, which he called the "Temple of Vaccinia" (Figure 4), where he vaccinated the poor for free $(10,17)$. After a decade of being honored and reviled in more or less equal measure, he gradually withdrew from public life and returned to the practice of country medicine in Berkeley. In 1810, his oldest son, Edward, died of tuberculosis. His sister Mary died the same year and his sister Anne 2 years later. In 1815, his wife, Catherine, died of tuberculosis (17). Sorrows crowded in on him, and he withdrew even further from public life. In 1820, Jenner had a stroke from which he recovered. On January 23, 1823, he visited his last patient, a dying friend. The next morning Jenner failed to appear for breakfast; later that day he was found in his study. He had had a massive stroke. Edward 


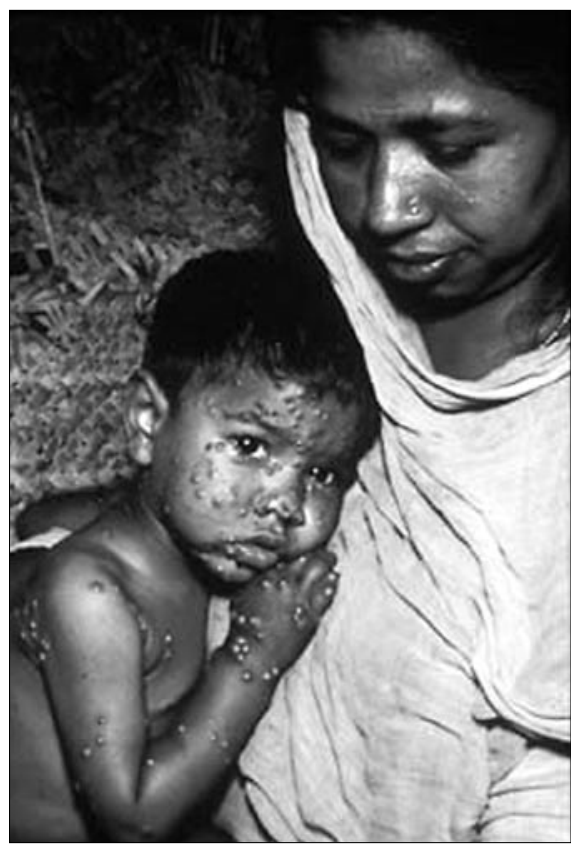

Figure 5. Smallpox in India, 1970s. Photo courtesy of the World Health Organization.

Jenner died during the early morning hours of Sunday, January 26, 1823. He was laid to rest with his parents, his wife, and his son near the altar of the Berkeley church.

\section{CONCLUSION}

Jenner's work represented the first scientific attempt to control an infectious disease by the deliberate use of vaccination. Strictly speaking, he did not discover vaccination but was the first person to confer scientific status on the procedure and to pursue its scientific investigation. During the past years, there has been a growing recognition of Benjamin Jesty (1737-1816) as the first to vaccinate against smallpox (21). When smallpox was present in Jesty's locality in 1774, he was determined to protect the life of his family. Jesty used material from udders of cattle that he knew had cowpox and transferred the material with a small lancet to the arms of his wife and two boys. The trio of vaccinees remained free of smallpox, although they were exposed on numerous occasions in later life. Benjamin Jesty was neither the first nor the last to experiment with vaccination. In fact, the use of smallpox and cowpox was widely known among the country physicians in the dairy counties of 18th-century England. However, the recognition of these facts should not diminish our view of Jenner's accomplishments. It was his relentless promotion and devoted research of vaccination that changed the way medicine was practiced.

Late in the 19th century, it was realized that vaccination did not confer lifelong immunity and that subsequent revaccination was necessary. The mortality from smallpox had declined, but the epidemics showed that the disease was still not under control. In the 1950s a number of control measures were implemented, and smallpox was eradicated in many areas in Europe and North America. The process of worldwide eradication of smallpox was set in motion when the World Health Assembly received a report in 1958 of the catastrophic consequences of smallpox in 63 countries (Figure 5). In 1967, a global campaign was begun under the guardianship of the World Health Organization and finally succeeded in the eradication of smallpox in 1977. On May 8, 1980, the World Health Assembly announced that the world was free of smallpox and recommended that all countries cease vaccination: "The world and all its people have won freedom from smallpox, which was the most devastating disease sweeping in epidemic form through many countries since earliest times, leaving death, blindness and disfigurement in its wake" (22).

Scientific advances during the two centuries since Edward Jenner performed his first vaccination on James Phipps have proved him to be more right than wrong. The germ theory of disease, the discovery and study of viruses, and the understanding of modern immunology tended to support his main conclusions. The discovery and promotion of vaccination enabled the eradication of smallpox: this is Edward Jenner's ultimate vindication and memorial.

1. Henderson DA, Inglesby TV, Bartlett JG, Ascher MS, Eitzen E, Jahrling PB, Hauer J, Layton M, McDade J, Osterholm MT, O’Toole T, Parker G, Perl T, Russell PK, Tonat K; Working Group on Civilian Biodefense. Smallpox as a biological weapon: medical and public health management. JAMA 1999;281: 2127-2137.

2. Lakhani S. Early clinical pathologists: Edward Jenner (1749-1823). J Clin Pathol 1992;45:756-758.

3. Hopkins DR. Princes and Peasants: Smallpox in History. Chicago: University of Chicago Press, 1983.

4. Barquet N, Domingo P. Smallpox: the triumph over the most terrible of the ministers of death. Ann Intern Med 1997;127(8 Pt 1):635-642.

5. Lyons AS, Petrucelli RJ II. Medicine-An Illustrated History. New York: Abradale Press, Harry N Abrams Inc, 1987.

6. Littman RJ, Littman ML. Galen and the Antonine plague. Am J Philol 1973;94:243-255.

7. Christopher GW, Cieslak TJ, Pavlin JA, Eitzen EM Jr. Biological warfare. A historical perspective. JAMA 1997;278:412-417.

8. Moore JC. The History of the Smallpox. London: Longman, 1815.

9. Gross CP, Sepkowitz KA. The myth of the medical breakthrough: smallpox, vaccination, and Jenner reconsidered. Int J Infect Dis 1998;3:54-60.

10. Willis NJ. Edward Jenner and the eradication of smallpox. Scott Med J 1997;42:118-121.

11. Stearns RP. Remarks upon the introduction of inoculation for smallpox in England. Bull Hist Med 1950;24:103-122.

12. Beall OT, Shryock RH. Cotton Mather: First Significant Figure in American Medicine. Baltimore: Johns Hopkins University Press, 1954.

13. Bardell D. Smallpox during the American war of independence. ASM News 1976;42:526-530.

14. Stark RB. Immunization saves Washington's army. Surg Gynecol Obstet 1977;144:425-431.

15. Thursfield H. Smallpox in the American war of independence. Ann Med Hist 1940;2:312-318.

16. Parish HJ. Victory with Vaccines: The Story of Immunization. Edinburgh: E \& S Livingstone, 1968.

17. Mullin D. Prometheus in Gloucestershire: Edward Jenner, 1749-1823. J Allergy Clin Immunol 2003;112:810-814.

18. Winkelstein W Jr. Not just a country doctor: Edward Jenner, scientist. Epidemiol Rev 1992;14:1-15.

19. Scott EL. Edward Jenner FRS and the cuckoo. Notes and Records of the Royal Society 1974;28(2):235-240.

20. Underwood EA. Edward Jenner, Benjamin Waterhouse and the introduction of vaccination into the United States. Nature 1949;163:823-828.

21. Pead PJ. Benjamin Jesty: new light in the dawn of vaccination. Lancet 2003;362:2104-2109.

22. World Health Organization. Global Commission for Certification of Smallpox Eradication. The Global Eradication of Smallpox: Final Report of the Global Commission for the Certification of Smallpox Eradication. Geneva: World Health Organization, 1980. 